\title{
Re: "Emergency Medicine Faculty Are Poor at Predicting Burnout in Individual Trainees: An Exploratory Study"
}

\section{To the Editor:}

W e read Dr. Lu's article with great interest. ${ }^{1}$ Burnout is a serious and growing condition in emergency medicine, and as the article suggests, it is significantly underrecognized. ${ }^{2}$ While the article is laudable in many respects, the authors do not spend much time discussing the ethical and professional implications of discovering serious negative mental states in residents as part of their study. How was this sensitive information handled after it was discovered? Were the residents informed if they tested positive or informed that their mentor thought they were burned out? Was the residency leadership or was their mentor informed of their status? Given this incredible sensitive information and its potential implications we think that it is important for them to comment on the consent process and the guidance they received from the human subject review board to make the article stronger in its own right and for setting precedent for future investigations.
Matthew L. Wong, MD, MPH and Edward Ullman, MD

Department of Emergency Medicine, Beth Israel Deaconess Medical Center, Boston, MA. (MLWong@bidmc.harvard.edu)

Supervising Editor: John H. Burton, MD

\section{References}

1. Lu DW, Lank PM, Branzetti JB. Emergency medicine faculty are poor at predicting burnout in individual trainees: an exploratory study. AEM Educ Train 2017;1:75-8.

2. Shanafelt TD, Hasan O, Dyrbye LN, et al. Changes in burnout and satisfaction with work-life balance in physicians and the general US working population between 2011 and 2014. Mayo Clin Proc 2015;90:1600-13. 